\title{
Practical experiences in auditing patient outcomes
}

\author{
M J Bardsley, J M Coles
}

Much of the recent effort in the development of clinical audit has focused on what Donabedian describes as the structure and process of care. ${ }^{1-3}$ There have been relatively few attempts at routinely monitoring outcome measures other than at the most basic level for example, mortality statistics. Most current health service information systems describe the activities undertaken by the service yet, as the Griffith's report ${ }^{4}$ pointed out, they tell us little about what actually happens to patients' health. Such information, though, is important within the clinical audit process and to any complete assessment of the efficiency and effectiveness of health services. ${ }^{5-7}$

This deficiency in health service information has several causes, including uncertainties over how to measure outcome and the difficulties and the perceived costliness of collecting the necessary data. However, recent pressures for better information on the quality of care, together with improved technologies in data capture and outcome measurement have made the assessment of patient outcomes more achievable.

The CASPE (Clinical Accountability, Service, Planning and Evaluation) study of monitoring patient outcomes started at Freeman Hospital in the autumn of 1988 as a feasibility study to examine ways in which practical outcome measures could be developed and included in clinical audit and decision making within the hospital. ${ }^{8}$ The study revolved around three key questions:

Is it possible to agree acceptable indicators of patient outcome with clinicians?

Is it possible to collect the information for routine monitoring of patient outcomes?

Does information on outcome lead to changes in practice?

This paper describes the progress made in this difficult area and identifies issues of general interest concerning outcome monitoring.

\section{Outcome measurement in the CASPE/ Freeman study}

The objectives of outcome measurement vary widely across studies and will necessarily affect decisions about the approach to be adopted and the scale of data collection. At one level outcome measurement may be part of the clinical process focusing on the individual patient and typically using clinical proxy measures of health rather than direct measures of patient wellbeing. ${ }^{9}{ }^{10}$ Beyond the individual patient, outcome measurement has often centred on individual projects such as detailed clinical trials ${ }^{11}$ or retrospective epidemiological studies - for example, of avoidable mortality. ${ }^{12} 13$ Studies have also examined the effect of patient and process variables on outcomes, ${ }^{14}$ the clinical decision making process, ${ }^{15}$ and economic cost utility. ${ }^{16}$

In the past few years the emphasis has been on building outcome measurement into the routine clinical management of departments and hospitals. Initiatives have included, in the United States, interhospital comparisons of outcomes for selected conditions and specialties $^{17}$ and, in the United Kingdom, identification of outcome measures based on existing data. ${ }^{18} 19$ Nationally, in the United Kingdom the confidential enquiries - for example, the confidential enquiry into perioperative deaths $(\mathrm{CEPOD})^{20}-$ come closest to an audit based approach to the continuous monitoring of outcomes. Such an approach accepts the total caseload, rather than specifying particular entry criteria, with the significance of particular presenting characteristics being examined a posteriori. The CASPE/Freeman study followed this latter approach and aimed at providing a routine information system that would regularly make available to clinicians indications of the success or failure of care against agreed criteria. As Ellwood pointed out in his lecture on outcomes management it was to be expected that "... standards and outcome measures would be constantly subject to modification based on the results of analysis and feedback." 21

\section{Developing local outcome criteria}

Donabedian defined outcomes in terms of "a change in patients' current and future health status that can be attributed to antecedent

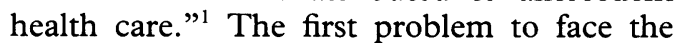
research team was therefore to identify practicable ways of monitoring health status. The work was undertaken in parallel in several specialties covering both acute and chronic illness and across the inpatient and outpatient base. The case types studied included diabetes, cholecystectomy, knee replacements, care of the elderly (rehabilitation in the acute hospital), and percutaneous transluminal coronary angioplasty (PTCA). We adopted a similar approach in each specialty with seven discrete steps being identified, as described below.

CHOOSING SUITABLE REFERENCE GROUPS In most of the areas examined a single condition was selected as an initial reference group around which to focus discussion. The choice of condition was guided by the 
following criteria: (a) a sufficiently large volume of cases to enable reasonable statistical results to be obtained and to represent a sizable proportion of the specialty's workload; (b) significance in terms of health status of the patient; (c) capability of reference to an agreed standard; (d) relevance to specific processes, areas of contention, or uncertainty in care; $(e)$ practicability of data collection.

In many circumstances the study found that the potential outcome measure was relevant across different disease groups - for example, avoidance of death or improved "wellbeing." However, even with these common measures variation was found between case types in, for example, the choice of relevant periods between measurements, the importance of different presenting characteristics, and the likely standards for comparison.

IDENTIFYING EXPECTED CHANGES IN HEALTH After a reference group had been identified the next step was to agree with clinicians on the changes in health they would expect to see (the patient outcomes) over specified periods. For some conditions - typically those resulting in an acute inpatient episode - the outcomes were the changes noted from admission to hospital to three months and 12 months after discharge. In the case of chronic conditions it was necessary to consider longer timescales, with outcomes being considered as the marginal change in the patient's health over time. These might be in terms of positive improvements in the patient or, alternatively, avoidance of a deterioration in health. The first time period typically started at the first contact with the service and continued until a follow up clinic or regular review appointment. When possible, the expected standards of outcome were agreed. However, given the novelty of some of the approaches, for example, patients' own view of their health status, absolute standards were not always achieved and the study had to accept general directional terms such as "all patients should show improvement."

IDENTIFYING POTENTIAL EFFECT MODIFIERS In monitoring the benefits of particular interventions it was important to identify any presenting characteristics that might affect the eventual outcome. This was particularly important as the study focused on secondary care, where potential improvements might have been limited by a patient's previous medical history. Such variables should then be used to define subsets of patients expected to achieve similar outcomes. For example the expected outcomes for young, otherwise healthy patients having cholecystectomy are likely to be different from those expected for elderly patients presenting with significant accompanying conditions. The practical importance of these variables in explaining observed differences in outcome can be evaluated once results become available.

In our experience there was a tendency to overspecify such characteristics. Variables such as obesity did not often seem to affect the eventual subdivision of the patients database, given that such subdivision would further dilute the sample size.

\section{IDENTIFYING DATA REQUIRED TO MONITOR} CHANGES

In most cases the relation between the outcome indicator and the type of data required to create it was clear and straightforward. For a clinical assessment of the patient important information will probably have already been collected in some form and the task will be to ensure the use of valid definitions, consistency of recording, and collection and translation of text from various manual systems to a single analysable form. However, new data collection systems were required to examine outcomes from the patient's perspective.

\section{IDENTIFYING THE BEST METHODS OF DATA} COLLECTION

The methods of data collection developed during the project showed strong similarities across specialties, although not all specialties required the full range of methods, which included (a) simple forms completed by clinicians or research staff, $(b)$ questionnaires completed by patients, (c) extracts from existing computerised and manual systems, (d) information from carers outside the hospital, and (e) information from lists of notification of deaths.

Though existing data sources, when supplemented with information from patients, were able to provide much of the information required, some additional data collection by clinical staff was needed. This had to be justified on the grounds that it replaced or improved existing methods of data collection, it provided other significant benefits, as information, or it was considered essential for the review of outcomes.

\section{PILOTING DATA COLLECTION}

The pilot stages of any project raise questions over the feasibility of collecting certain items of information, particularly on a continuing basis. The different methods of data collection that emerged were tried and evaluated in terms of reliability and consistency. Issues over the definition of data items also arose at this stage - for example, how is unstable angina defined? The review of data collection systems and definitions formed part of the feedback process and the discussion of results. These systems underwent an iterative development which responded to demands for new items of data to be added withoug losing the necessary stability of key data items needed for longer term trend analysis.

FEEDBACK OF RESULTS

The purpose of collecting outcome information was to inform clinical practice and identify possible areas for change. This was undertaken within an audit framework with results being presented at regular meetings with the clinical staff concerned. Data were fed back to clinicians which summarised changes 
in individual patients; provided specific reports on patients with "poor outcomes"; described the changes that had taken place, on aggregate and when subdivided into key groups.

It was recognised that, increasingly, hospital management will need to become concerned at the aggregate level with the successful delivery of care through the contracting process and may well need outcome figures to support this process. Even here, careful interpretation of the data will be required.

\section{Results}

The findings are reported in relation to the three main questions of the study.

OUTCOME MEASURES

The indicators that emerged considered different dimensions of outcome as potential candidate measures and ranged from specific clinical and laboratory assessments to more general descriptions of health and patient wellbeing. It is becoming increasingly accepted that the patient's perspective is critical in assessing the effectiveness of health care, and experience in polling patients on different aspects of their health, quality of life, or satisfaction with treatment ${ }^{22} 23$ is growing.

Table 1 summarises the sets of indicators used for cholecystectomy, knee replacement, and angioplasty and table 2 those for diabetes and care of the elderly. The range of outcome measures identified and used in this study are described below.

Deaths and survival - Though the observed rate at which patients die varies widely across conditions, in most settings survival is a critical outcome measure.

Major adverse events - After treatment there may occur possible serious health related events, typically indicators of worsening patient health, which might be considered as proxies of outcome. These include readmissions, attendance at accident and emergency, and repeat angioplasty in stable angina patients.

Treatment complications ocurring over a short period - for example, infections, urine retention, deep vein thrombosis, and other specific complications related to particular body systems - might be considered important in assessing outcomes.

Technical success of treatment - In some circumstances the successful administration of the treatment itself may be considered an outcome - though it is also a process measure; the best example from this study is dilation of vessels during angioplasty.

Relief of specific symptoms or problems was

Table 1 Examples of outcome indicators for cholecystectomy, PTCA, and knee replacement

\begin{tabular}{|c|c|c|c|}
\hline & Cholecystectomy & Angioplasty or PTCA & Knee replacement \\
\hline $\begin{array}{l}\text { Successful treatment } \\
\text { or care }\end{array}$ & $\begin{array}{l}\text { Successful removal of gallstones } \\
\text { and no immediate complications }\end{array}$ & Vessel dilated during PTCA & $\begin{array}{l}\text { Successful operation with no } \\
\text { immediate complications } \\
\text { Minimal loosening of prosthesis }\end{array}$ \\
\hline $\begin{array}{l}\text { Treatment } \\
\text { complication }\end{array}$ & Minimal postoperative problems & Minimal problems after PTCA & Minimal postoperative problems \\
\hline $\begin{array}{l}\text { Specific symptom or } \\
\text { problem }\end{array}$ & $\begin{array}{l}\text { Relief of pain, vomiting, } \\
\text { distension, bowel function, } \\
\text { flatulence, fatty foods }\end{array}$ & $\begin{array}{l}\text { Decreased anginal pain, } \\
\text { increased walking distance }\end{array}$ & Improved knee function \\
\hline General health & Improved NHP score & Improved NHP score & Improved NHP score \\
\hline Major adverse events & No related readmissions & $\begin{array}{l}\text { No related readmissions, } \\
\text { especially CABG, repeat PTCA }\end{array}$ & $\begin{array}{l}\text { No related readmission, repeat } \\
\text { operations }\end{array}$ \\
\hline Death & None & $\begin{array}{l}\text { None for stable angina } \\
\text { Minimal for unstable angina }\end{array}$ & None \\
\hline Other indicators & $\begin{array}{l}\text { No related visits to accident and } \\
\text { emergency }\end{array}$ & Reduced potency of medication & \\
\hline $\begin{array}{l}\text { Important } \\
\text { discriminatory } \\
\text { variables }\end{array}$ & Age, acuity, comorbidity & $\begin{array}{l}\text { Age, angina type, degree of } \\
\text { stenosis, previous history }\end{array}$ & $\begin{array}{l}\text { Age, severity of disease, damage } \\
\text { to knee (on } x \text { ray) }\end{array}$ \\
\hline
\end{tabular}

PTCA = percutaneous transluminal coronary angioplasty.

NHP $=$ Nottingham health profile

$\mathrm{CABG}=$ Coronary artery bypass grafting.

Table 2 Examples of outcome indicators for diabetes and care of the elderly.

\begin{tabular}{|c|c|c|}
\hline & Diabetes & $\begin{array}{l}\text { Care of the elderly } \\
\text { (rehabilitation) }\end{array}$ \\
\hline Successful treatment or care & $\begin{array}{l}\text { Improved metabolic control } \mathrm{HbA}_{\mathrm{l}} \text {, body } \\
\text { mass index } \\
\text { Control of risk factors (for example, } \\
\text { hypertension, cholesterol) }\end{array}$ & Alleviation of acute medical condition \\
\hline \multicolumn{3}{|l|}{ Treatment complication: } \\
\hline Specific symptom or problem & $\begin{array}{l}\text { Minimal incidence of diabetic } \\
\text { complications - that is, eyes, kidney, } \\
\text { vascular disease, nervous system, etc }\end{array}$ & $\begin{array}{l}\text { Improvement in Barthel score (basic } \\
\text { function) } \\
\text { No worsening mental test score }\end{array}$ \\
\hline General health & $\begin{array}{l}\text { Improvement or maintenance of sickness } \\
\text { impact profile }\end{array}$ & \\
\hline Major adverse events & Minimal episodes hypo- or hyperglycaemia & Minimal readmissions \\
\hline Death & & Minimal (with caveats) \\
\hline Other indicators & Patient knowledge of diabetes & $\begin{array}{l}\text { Minimise burden on carers } \\
\text { Maintain independence of home } \\
\text { environment }\end{array}$ \\
\hline Important discriminatory variables & Age, sex, diabetes type & Medical condition, route of admission \\
\hline
\end{tabular}


thought by clinicians to be important. For example, information on anginal pain after coronary angioplasty, flatulence after cholecystectomy, and other such symptoms was obtained directly from the patients, when possible.

General health status - One of the benefits of care should be in a marginal improvement in health status as perceived by the patient, relative either to a baseline value before the intervention or to the expected change that would have occurred without intervention. In some cases "good" outcomes will be about maintaining health status in the face of a chronic disease process.

MEASURING OUTCOMES FROM THE PATIENTS' PERSPECTIVE

In discussions with the clinicians involved it became clear that patients' views of perceived changes in their health over the period of a particular intervention would be an important contribution. With the large number of tried and validated instruments already described, ${ }^{24}$ some developed over many years, it seemed inappropriate to embark on devising further measures before ensuring that none of the existing measures would suffice. However, ambiguities in the use of the terms health status, functional status, wellbeing, and quality of life and considerable variation in what are considered the relevant dimensions of health exist across such measures. Ware suggested five generic concepts: physical health, mental health, social functioning, role functioning, and general health perception $\mathrm{s}^{25}$ which are reflected in many measures. These categories overlap slightly, but they are a useful framework for considering the variety of

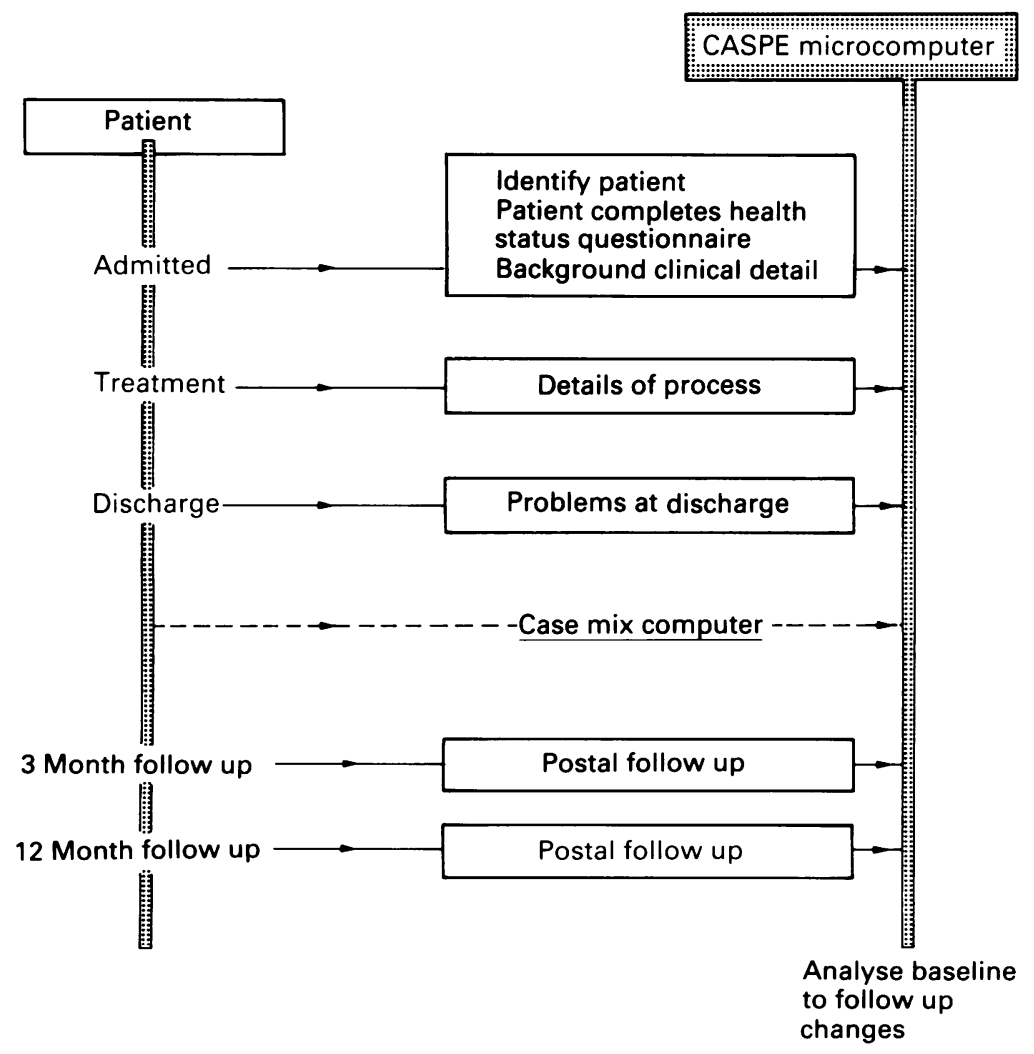

Fig 1 Data collection model for general hospital inpatient treatment outcome measures in the different specialties. In selecting the instrument for any particular condition the following criteria were used.

- The instrument was an established and validated tool which had been used in the United Kingdom

- It had been used in a similar patient group or if not the questions or items in the scale were deemed relevant to that patient group

- It was expected to be sufficiently responsive to show longitudinal change after intervention

- It was as quick and easy as possible to administer, which effectively meant a patient completed instrument

- It was a generic rather than a disease specific measure. ${ }^{26}$

One of the measures selected for this study was the Nottingham health profile (NHP), which has been used for various types of patients in cross sectional studies ${ }^{27}$ and for determining longitudinal change. ${ }^{28} 29$ Compared with some other instruments it is fairly short and easy to administer when completed by the patient. The results in this project found the instrument to be sufficiently responsive in detecting changes in a patient's health after cholecystectomy, knee replacements and PTCA. ${ }^{8}$

One of the disadvantages of the NHP is that a patient's problems need to be fairly severe to score, and the modal response for a normal population will be zero. ${ }^{30}$ In chronic conditions, for example, the questions were not sufficiently sensitive, and a different scale, based on the sickness impact profile, was tested. ${ }^{31}$ In this case the advantages of using a familiar instrument (and one common to different conditions) was outweighed by the need to use a measure that was thought to be better suited to the particular case type. A similar consideration lay behind the choice of the Barthel scale ${ }^{32}$ for the elderly. This simple scale is based on activities of daily living, can be assessed by clinical staff, and was found to reflect some of the key goals of care in this specialty.

Patient assessed measures were used in conjunction with other indicators and the inevitable overlaps between measures were used to test their validity and sensitivity, both of which were found to be satisfactory.

PRACTICALITIES OF DATA COLLECTION

The choice of conditions (two chronic and three acute) in this project was reflected in the data collection methods that developed in the early part of the study. Two general models (figures 1 and 2) were developed, reflecting the different types of care and, specifically, the need for continued monitoring over longer timescales in the case of chronic conditions.

In the acute model (fig 1) the benefits of the intervention were expected to emerge within a fairly well defined period. Data collection required a pretreatment baseline assessment of the patient supplemented by detail at discharge and, most importantly, at follow up after an agreed period, say three months and 12 months. Success was measured by the changes from baseline to follow up. Patients 


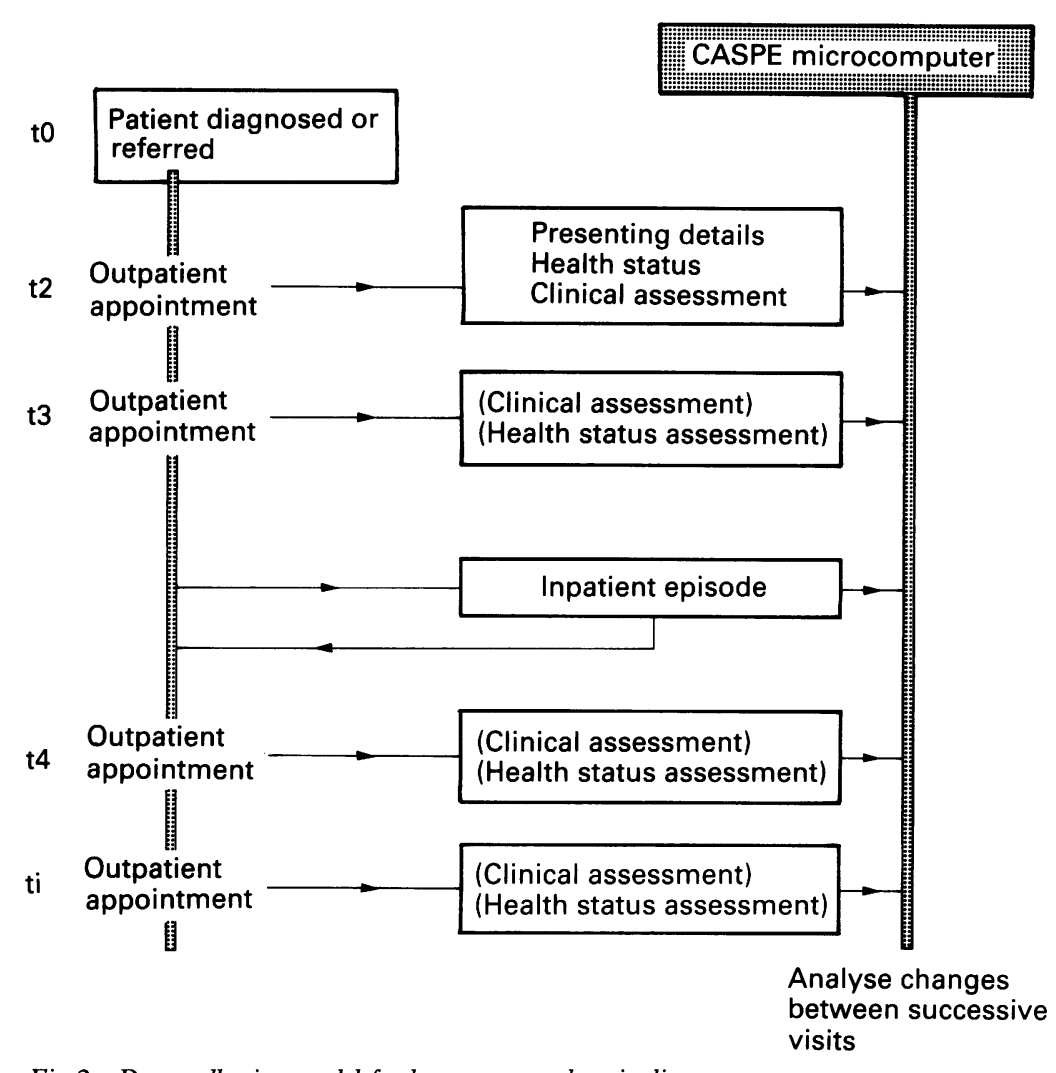

Fig 2 Data collection model for long term or chronic disease

whose initial treatment failed, for example, repeat PTCAs, caused some logistical difficulties for the analysis, but these difficulties were overcome by considering the first intervention as an important presenting characteristic for the second episode.

In the chronic model (figure 2) there are no clear end points at which to measure outcomes, which are in any case typically concerned with maintaining health and preventing deterioration. The clearest example in the study was the annual review process in diabetes with all clinic patients being seen at this hospital at least once a year. The details of the patient's health were captured at each visit, and outcomes were expressed as longitudinal change between visits. The exploitation of databases on local clinical microcomputers can fulfil a useful role in this respect by maintaining a register of patients, recording some of the basic information (which may be integral to most consultations), and enabling longitudinal comparisons across groups of patients and over different periods to determine the process-outcome relation. In many cases patients with chronic disease will from time to time experience a stay in hospital. These were regarded as events within the longer term course of treatment, although the specific goals of the inpatient episode are studied separately - as, for example, in diabetes inpatient studies when the acute treatment model is more appropriate to examine short term changes.

Among other lessons learnt from the data collection systems in the study were that

- Patient completed postal questionnaires were easy to administer and achieved very high $(90 \%)$ response rates
- Retrospective data collection from notes was feasible, although locating notes and ensuring consistency of definitions were among the problems identified

- Collecting data in specific time slots, for example, at a particular outpatient appointment, may prove expensive

- When possible, routine systems and existing databases should be exploited, if necessary by adding one or two more data items

- Death notifications systems were often inadequate and caused unneccessary distress when attempts were made to approach patients who had died after an inpatient stay.

BRINGING ABOUT CHANGE

The raison d'être for the interest in monitoring outcomes of care and indeed for the audit process in general must be to enhance knowledge about how to achieve improved benefits for the patient and, having obtained that knowledge, to bring about change to effect such improvements. The short timescale of the study (just over two years to establish the research, collect, and report back on data to 12 month follow up) meant that substantial changes in practice were unlikely. However, some changes in practice were noted, together with attitudinal changes of clinicians and changes in the collection and use of information on the quality of care. Some instances are given in the following paragraphs.

Changes in attitudes - The commitment of the clinical staff to outcome measurement has been considerable and has grown throughout the study. As well as committing time to discussing the results some clinical staff have also made their own research staff available to collect and collate data. They have also been willing to share data, discuss new and fairly advanced instruments, and develop new areas of study. The hospital trust has shown its commitment to the project by funding the maintenance of these systems since research funds ended. Perhaps as important has been the acceptance during the course of the project of the value of the patient's perceptions in assessing care. These variables are now considered alongside clinical indicators when outcomes are reviewed. In care of the elderly the main carer has also been providing information which is being used by the nurses to highlight potential problem areas. The pooling of outcome information from different perspectives is accepted as being highly desirable.

Changes in gathering data - In most specialties concerned the study benefited the way information was being collected for audit. Generally, a greater degree of consistency in recording was required, and some additional data items were sought by particular clinicians; standardised knee scores in orthopaedics and the care giver strain scale are two examples. Examining data in different ways, for example, longitudinally, was found to be valuable, although comparisons with "bench marks" in published reports and elsewhere proved 
difficult owing to differences in the context or process of data gathering. Establishing standards, particularly in the newer health status measures, requires a period of preliminary analysis - a learning cycle - mainly to establish the proportion of patients that might be expected to achieve a given goal.

Changes in practice - Despite the limited time available some examples of changes in practice could be attributed to the project. These include the introduction of new guidelines in outpatients and changes to the content of the educational programme for diabetes. Improved targeting for individual patients and an awareness that some orthopaedic patients, especially younger patients, may have an unrealistically high expectation of outcomes are now being examined. Other topics identified for further action include opportunities for reducing medication in cardiology and replacing an unsatisfactory laboratory assay identified from analysis of the outcomes database.

\section{Discussion and conclusions}

This study is one of the few to date that has tried to apply the same basic methodological framework to developing outcome information in several different specialties. The method of working did not seek to build a common data set to be imposed across specialties but gave priority to developing sets of indicators of value to individual clinicians. However, as identified earlier, similar outcome dimensions were found across the conditions studied as was some consistency in the measurement instruments used.

During the study different properties of particular outcome indicators developed became apparent. These properties, which may be of use in determining the value of any single indicator within a particular approach, are described below. They are considered as lying on three (not necessarily continuous) axes.

Clinical or professional viewpoint versus patient's perspective - Some indicators were firmly grounded in the clinical view of the disease process. For example, the laboratory measures which monitor blood glucose control in diabetes are far removed from being direct descriptions of the daily wellbeing. The clinical assumption in this case is that well controlled blood sugar will minimise the serious longer term health problems of diabetes. Indicators such as health status instruments reflect the patient's perception more directly while other indicators can be positioned between the two extremes.

Direct versus indirect measures, processes, and proxies - The second axis concerns the extent to which the measure is a direct reflection of a particular event or patient problem or a proxy for that problem. For example, a readmission after cholecystectomy does not describe the patient but rather a health care process. Assuming the readmission is related to the cholecystectomy, it still need not reflect a poor outcome of the original procedure. Ideally, measures should be direct descriptions of a patient's health, yet in many cases descriptors of process are adequate if they can be genuinely linked to health - for example, a cardiac patient being admitted for a repeat coronary angioplasty. As identified earlier, in practice the distinction between process and outcome becomes blurred.

Strong links to care (causality) versus uncertain links - The final axis considered concerns the extent to which changes in a measure can be causally linked to a particular process, for example, changes in the general indicators of wellbeing can be subject to many external variables. How much of the improvement or deterioration in a patient's score is due to the care given? This axis is also likely to reflect whether an indicator is general and applicable across patient groups as opposed to a detailed indicator for specific conditions.

Positioning each measure on these axes can be useful in highlighting possible redundancy in the data being collected - for example, when measures are closely aligned on all three axes only one of them is likely to be needed or in identifying the nature of outcome monitoring for different specialties or types of care.

As instanced above, process and outcome measures need joint interpretation. One of the problems experienced in the study lay in the uncertainty that could exist between the care delivered and the outcomes that resulted. This was especially true when there was a lack of experience in interpreting the instruments or indicators used and also a lack of comparative data. The problem was stated by Lohr: "The degree to which outcomes can be directly related to processes of care continues to be especially problematic. I view the continued debate about whether processes or outcomes are preferable as fundamentally unproductive as both are needed." 33

For this reason therefore it was clear that the explanation and the identification of how results might be improved had to come from the clinicians themselves. The definition of outcome objectives and the method of monitoring results had to be agreed with clinicians locally if the audit and review processes were to be effective. Without such involvement outcome analysis becomes merely "a black box," reporting what is going on but, with little scope to help clinicians in interpreting data, ${ }^{34}$ with the inherent risk of a loss of credibility.

The results of the study suggest that this type of information can act at several different levels in examining the need for changes in practice. As well as looking at the care and treatment of individual patients, outcome analysis can help in determining:

- which cases to treat

- choice of mode of treatment for particular patients

- the way care is given or organised for groups of patients

- the way a service as a whole is organised

- choices between different services.

All the clinicians involved in this study expressed a wish to continue monitoring outcomes and think the work has been 
beneficial. Indeed, the work is continuing through various funding agencies, including the hospital trust. The study has shown that a non-threatening environment can be established in which critical analysis of the success of clinical practice becomes an accepted part of the culture. ${ }^{35}$ In common with process based audit systems, however, outcome information requires that an appropriate organisational framework is present to maximise its value. Taken in isolation, a more explicit knowledge of either the process of care or patient outcomes may be of interest to the professional staff involved yet produce little in effecting changes in practice or use of resources. The goal should be to bring together clinicians and managers, both of whom are empowered by the necessary information on process, outcome, and resource use, to develop approaches and agree decisions on how to improve health care. The pieces of this jigsaw are now all present within the NHS but development is fragmented geographically and across specialties. It may not, however, be too long before it is possible to put them all together.

We thank all the staff at Freeman Hospital who helped during this project. The work was funded by the research managemen division of the Department of Health.

1 Donabedian A. Explorations in quality assessment and monitorning. Vols 1-3. Ann Arbor, Michigan: Health Administration Press, 1985.

2 Gruer R, Gunn A, Gordon D, Ruckley C. Audit of surgical audit. Lancet 1986;i:23-5.

3 Shaw C. Medical audit. A hospital handbook London: King's Fund Centre, 1989

4 Griffiths R. NHS management inquiry. London: Department of Health and Social Security, 1983.

5 Roberts H. Outcome and performance in health care. London Public Finance Foundation, 1990. (Discussion pape 33.)

6 Brook RH, Kamberg CJ. General health status and outcome measurement: a commentary on measuring functional status. Fournal of Chronic Diseases 1987; 40(suppl): 131-6S

7 Hopkins A, Costain D, eds. Measuring the outcomes of medical care. London; Royal College of Physicians, 1990.

8 Bardsley $\mathrm{M}$, Beveridge P, Byrne G, Coles J, Deardin L, Goodfellow J, et al. The CASPE/Freeman outcomes study. Goodfellow J, et al. The CASPE/Freeman outcom

9 Nelson EC, Berwick DM. The measurement of health status in clinical practice. Med Care 1989;27(suppl) S76-89.

10 Dickinson EJ, Young A. A framework for medical assessment of functional performance. Lancet 1990 335:778-9.
11 Cochrane A. Effectiveness and efficiency: random reflections on health services. London: Nuffield Provincial Hospitals Trust, 1972.

12 Charlton J, Hartley R, Silver R, Holland W. Geographica variations in mortality from conditions amenable to medical intervention in England and Wales. Lancet 1983;i:691-6.

13 Rutstein DD. Measuring the quality of medical care. New Engl f Med 1976;294:582-8.

14 Wennberg JE, Mulley AG, Hanley D, Timothy RP, Fowler FJ, Roos NP, et al. An assessment of prostatectomy for benign urinary tract obstruction: geographic variation and the evaluation of medical care outcomes. $f A M A$ 1988;259:3027-30.

15 Weinstein M, Coxson PG, Williams LN, Pass TM, Stason NB, Goldman L. Forecasting coronary heart disease incidence, mortality and cost: the coronary heart disease policy model. Am f Public Health 1987;77:1417-26.

16 Gudex C. QALYs and their use by the National Health Service. York: Centre for Health Economics, University of York, 1986. (Discussion paper No 20.)

17 Tarlov AR, Ware JE, Greenfield S, Nelson EC, Perrin E, Zubkoff $M$. The medical outcomes study. An application of methods for monitoring the results of medical care. of methods for monitoring

FAMA 1989;262:925-30.
Middleton JD. A discussion paper on outcomes for a nonteaching district. Community Med 1987;9:343-9.

19 Charlton JRH, Bauer R, Lakhani A. Outcome measures for district and regional health care planners. Community Med 1984;6:306-15.

20 Buck N, Devlin HB, Lunn JN. Report of a confidential enquiry into perioperative deaths. London: Nuffield Provincial Hospitals Trust, 1987.

21 Ellwood PM. Shattuck Lecture - Outcomes management A technology of patient experience. $N$ Engl $₹ \mathrm{Med}$ A technology of pat

22 Fries J. Towards an understanding of patient outcome measurement. Arthritis Rheum 1983;26:697-704.

23 Cleary P, McNeil B. Patient satisfaction as an indicator of quality of care. Inquiry 1988;25:25-36.

24 Spilker B, Molinek FR, Johnston KA, Simpson RL, Titson $\mathrm{HH}$. Quality of life bibliography and indexes. Med Care 1990;28(suppl):DS $1-77$.

25 Ware J. Standards for validating health measures: definition and content. Fournal of Chronic Diseases 1987;40: 473-80.

26 Patrick DL, Deyo RA. Generic and disease-specific measures in assessing health status and quality of life. Med Care 1989;27(suppl):S217-32.

27 Hunt SM, McEwen J, McKenna SP. Perceived health: age and sex comparisons in a community. $f$ Epidemiol Community Health 1984:38:156-60.

28 Hunt SM, McEwen J, McKenna SP. Measuring health status Beckenham: Croom Helm, 1986.

29 O'Brien BJ, Banner NR, Gibson S, Yacoub MH. The Nottingham Health Profile as a measure of quality of life following combined heart and lung transplantation. $f$ Epidemiol Community Health 1988;42:232-43.

30 Kind P, Carr-Hill R. The Nottingham health profile: a useful tool for epidemiology? Soc Sci Med 1987;25: 905-10.

31 Bergner M, Bobbitt RA, Carter WB. The Sickness Impact Profile: development and final testing of a health status Profile: development and final testing
measure. Med Care 1981;19:787-805.

32 Mahoney FI, Barthel DW. Functional evaluation: the Barthel index. Maryland State Medical fournal 1965; 14:61-5.

33 Lohr KN. Outcome measurement: concepts and questions. Inquiry 1988;25:37-50.

34 Shaw CD. Clinical outcome indicators. Health Trends 1989;21:37-9.

35 Shaw CD, Costain DW. Guidelines for medical audit: seven principles. BMF 1989;299:498-9. 